\title{
Ferrocene Metallopolymers of Intrinsic Microporosity (MPIMs)
}

Tianran Zhai, ${ }^{a}$ Kenson Ambrose, Audithya Nyayachavadi, Kelly G. Walter, ${ }^{\mathrm{c}}$ Simon Rondeau-Gagné, ${ }^{\mathrm{b}}$ and Jeremy I. Feldblyum*a

${ }^{a}$ Department of Chemistry, The University at Albany, State University of New York, Albany, NY, 12222, United States.Email:jfeldblyum@albany.edu

${ }^{b}$ Department of Chemistry and Biochemistry, University of Windsor, Windsor, ON, N9B 3P4, Canada. ${ }^{c}$ Department of Microbiological Sciences, North Dakota State University, Fargo, ND, 58108

\begin{abstract}
We show here that non-network metallopolymers can possess intrinsic microporosity stemming from contortion introduced by metallocene building blocks. Metallopolymers constructed from ferrocenyl building blocks linked by phenyldiacetylene bridges are synthesized and possess BET surface areas up to $400 \mathrm{~m}^{2} / \mathrm{g}$. As solubility imparted by pendant groups reduces porosity, copolymerization is used to simultaneously improve both accessible surface area and solubility. Spectroscopic analysis provides evidence that mixed valency between neighboring ferrocenyl units is supported in these polymers.
\end{abstract}

Microporosity affords opportunities for unique and guest-dependent optical and electronic functionality. ${ }^{1}$ However, the network (cross-linked) structure of most porous materials limits their solution processability and hence their utility in applications where high quality thin films are necessary, such as membrane-based separations, electronic devices, and energy storage..$^{2-4}$

Polymers of intrinsic microporosity (PIMs), ${ }^{5}$ in contrast to most $^{6}$ other microporous solids, are soluble in common organic solvents, allowing simple formation of high quality films by solutioncasting methods. ${ }^{7}$ While PIMs have achieved notable success for molecular sorption and separation, ${ }^{7,8}$ their optical and electronic properties remain largely unexplored - a consequence of the structural motifs most commonly used in PIMs, which lack backbone conjugation. ${ }^{9}$ Several conjugated PIMs have been reported, ${ }^{10-13}$ however, the backbone contortion that generates intrinsic microporosity in these polymers may also disrupt overlap between (intrachain) neighboring $\pi$ orbitals.

In this communication, we show that porosity, solubility, and intrachain electronic communication are not mutually exclusive. Main-chain metallopolymers rely on covalent or coordination bonds between metal and non-metal elements for the connectivity of the polymer chain. It is well- established that some of these polymers can support (semi)conductivity, ${ }^{14}$ however, porosity in these linear (non-network) polymers has remained unstudied. In this work, we show that polymers based on aryleneethynylene-bridged ferrocene units can in fact be porous. We also demonstrate a delicate balance between porosity and solubility: these characteristics are not mutually exclusive, but require careful polymer design to achieve simultaneously. Finally, we show that, consistent with previous reports, intrachain electronic communication is supported in these polymers.

Ferrocene aryleneethynylene polymers were prepared via Pd-catalyzed polycondensation ${ }^{15}$ as shown in Scheme 1. Following the method reported by Yamamoto's group, ${ }^{16}$ substituted 1,4diethynylbenzene monomers were coupled with 1,1diiodoferrocene $\left(\mathrm{FcI}_{2}\right)$ by Sonogashira coupling ${ }^{17,18}$ (Scheme 1). Crude polymers were extracted, precipitated, and washed with organic solvents experimental details can be found in Section 1.3 of the Electronic Supporting Information (ESI)]. Table 1 summarizes the results of polymerization.

We began by synthesizing P2. Although this polymer was obtained relatively high yield (79\%), precipitation of the polymer occurred soon after initiating polymerization. We hypothesized that

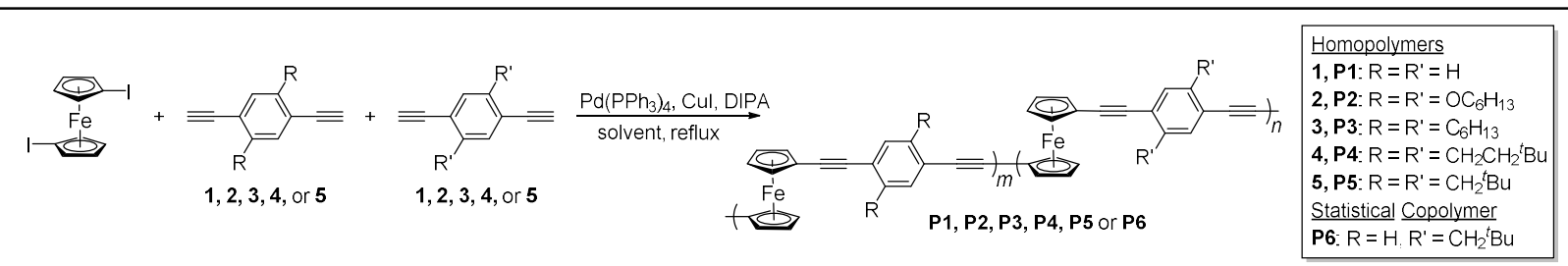

Scheme 1. Synthesis of ferrocene-based homopolymers and 1:1 statistical copolymer P1-P6 by Pd-catalysed polycondensation. 
Table 1. Preparation and properties of ferrocene polymers P1-P6.

\begin{tabular}{|c|c|c|c|c|c|c|c|c|c|}
\hline Polymer & Method $^{a}$ & Yield & $\begin{array}{c}M_{n}{ }^{b} \\
(\mathrm{~g} / \mathrm{mol})\end{array}$ & $\begin{array}{c}M_{W}^{b} \\
(\mathrm{~g} / \mathrm{mol})\end{array}$ & $\emptyset_{\mathrm{M}}$ & $\begin{array}{c}\pi-\pi^{*} \lambda_{\max } \\
(\mathrm{nm})^{c}\end{array}$ & \begin{tabular}{|c|}
$\mathrm{d}-\mathrm{d} \lambda_{\max }$ \\
$(\mathrm{nm})^{c}$
\end{tabular} & IVCT $\lambda_{\max }(\mathrm{nm})^{c}$ & $\begin{array}{c}\text { HOMO-LUMO } \\
\text { gap }(\mathrm{eV})^{\mathrm{c}}\end{array}$ \\
\hline P1 & $\mathrm{B}$ & $27 \%$ & 1,215 & 1,487 & 1.2 & 333 & 447 & 1642,1669 & 1.35 \\
\hline $\mathbf{P 2}$ & $\mathrm{A}$ & $79 \%$ & 5,930 & 6,542 & 1.1 & 333 & 443 & 1642 & 1.20 \\
\hline P3 & $\mathrm{A}$ & $32 \%$ & 12,485 & 16,876 & 1.4 & 297 & 444 & 1642,1711 & 1.54 \\
\hline P4 & $\mathrm{B}$ & $10 \%$ & 2,531 & 2,889 & 1.1 & 313 & 453 & 1642,1698 & 1.37 \\
\hline P5 & B & $22 \%$ & 1,223 & 1,574 & 1.3 & 307 & 453 & Not observed & 1.04 \\
\hline P6 & $\mathrm{B}$ & $20 \%$ & 11,126 & 16,491 & 1.5 & 292 & 452 & 1642,1672 & 1.31 \\
\hline
\end{tabular}

${ }^{a}$ Method A: 1.0 eq. of substituted 1,4-diethynylbenzene per 1.0 eq. of $\mathrm{FcI}_{2}$ was added. Catalyst: 0.04 eq. $\mathrm{Pd}\left(\mathrm{PPh}_{3}\right)_{4}$ and 0.04 eq. of $\mathrm{CuI}$ per 1.0 eq. of the monomer. Base: excess of diisopropylamine (DIPA, 86 eq.). Method B: 1.0 eq. of substituted 1,4diehtynylbenzene per 1.0 eq. of $\mathrm{FcI}_{2}$ was added. Catalyst: 0.04 eq. $\mathrm{Pd}\left(\mathrm{PPh}_{3}\right)_{4}$ and 0.04 eq. of $\mathrm{CuI}$ per 1.0 eq. of the monomer. Base: 1.2 eq. DIPA. ${ }^{b}$ Measured by high-temperature size exclusion chromatography in $1,2,4$-trichlorobenzene at $180^{\circ} \mathrm{C}$. ${ }^{c}$ Determined from diffuse reflectance spectroscopy measurements.

termination of polymerization occurred due to the poor solubility of the polymer in the synthesis solvent (toluene). Furthermore, the formation of short chains due to rapid precipitation opposes our goal of achieving intrinsic microporosity, as we hypothesize that porosity increases with chain length (at least for short chains). ${ }^{19}$ For this reason, we used dichloromethane (DCM) as the solvent for further polymerization. Indeed, the weight-average molecular weight $\left(M_{W}\right)$ of $\mathbf{P 3}$ obtained by hightemperature size exclusion chromatography (SEC) was significantly greater than that of the chemically similar P2. As the use of DCM was expected to lead to higher $M_{W}$, the higher $M_{W} \mathrm{~S}$ of polymers synthesized with DCM reduced their solubilities. Hence, analysis by SEC using 1,2,4trichlorobenzene as the eluent at $180{ }^{\circ} \mathrm{C}$ led to a wide range of $M_{w}$ s between 1.3 and $16.8 \mathrm{kDa}$, with the lowest values corresponding to the

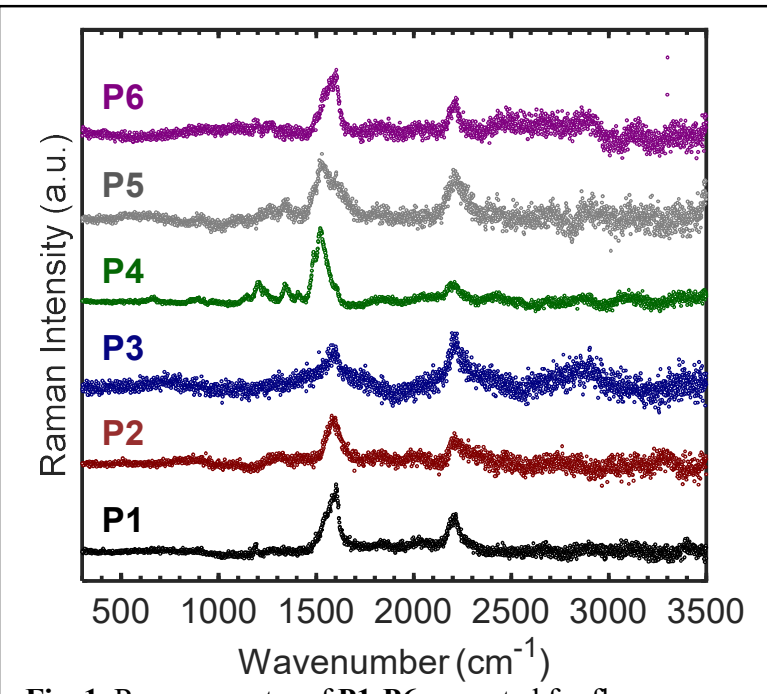

Fig. 1. Raman spectra of P1-P6 corrected for fluorescence background. Raw data are shown in Fig. S60. homopolymers empirically exhibiting the lowest solubilities (Table S5). The homopolymers with the greatest apparent solubilities in 1,2,4trichlorobenzene, $\mathbf{P 2}$ and $\mathbf{P 3}$, also exhibited the highest values of $M_{w}$ (Table 1). The relatively narrow dispersities measured for these polymers is also consistent with our contention that solubility limits the measured $M_{w} \mathrm{~s}$, as step growth polymers should exhibit dispersity close to $2 .{ }^{20}$ Artificially low dispersities can be obtained when only the lower molecular mass polymer fractions are dissolved. ${ }^{21}$

Analysis by ${ }^{1} \mathrm{H}$ NMR was also challenging due to the limited solubility of most of the homopolymers reported here. Analysis of P4, the polymer exhibiting the greatest solubility in $\mathrm{CDCl}_{3}$, exhibited broad signals characteristic ${ }^{22,23}$ of polymers in solution (Fig. S17). The resonances at ca. $7 \mathrm{ppm}, 4 \mathrm{ppm}$, and 1-2 ppm can be assigned to phenyl protons, Fc protons, and neohexyl protons, respectively. A weak resonance attributable to terminal $-\mathrm{C} \equiv \mathrm{H}$ protons (ca. 3 ppm) was also observed. The integration ratio between these terminal protons and those of the Fc protons is 1:53, corresponding to an average degree of polymerization of 6.7 , in reasonable agreement with that determined by SEC (5.3).

Analysis of P1-P6 by Raman spectroscopy (Fig. 1) confirmed that all polymers contain the expected $v(C \equiv C)$ scattering peak of disubstituted acetylene $\mathrm{e}^{24,25}$ at ca. $2200 \mathrm{~cm}^{-1}$. The peaks in the $1500-1600 \mathrm{~cm}^{-1}$ range are assigned to symmetric stretches of the polymers' arylene segments. ${ }^{26}$ The $v(\mathrm{C}-\mathrm{H})^{25}$ and $v(\mathrm{Fc}-\mathrm{I})^{27}$ vibrations, corresponding to terminal acetylene $\left(\sim 3300 \mathrm{~cm}^{-1}\right)$ and terminal $\mathrm{FcI}_{2}$ (ca. $1140 \mathrm{~cm}^{-1}$ and $880 \mathrm{~cm}^{-1}$ ) are not observable, 

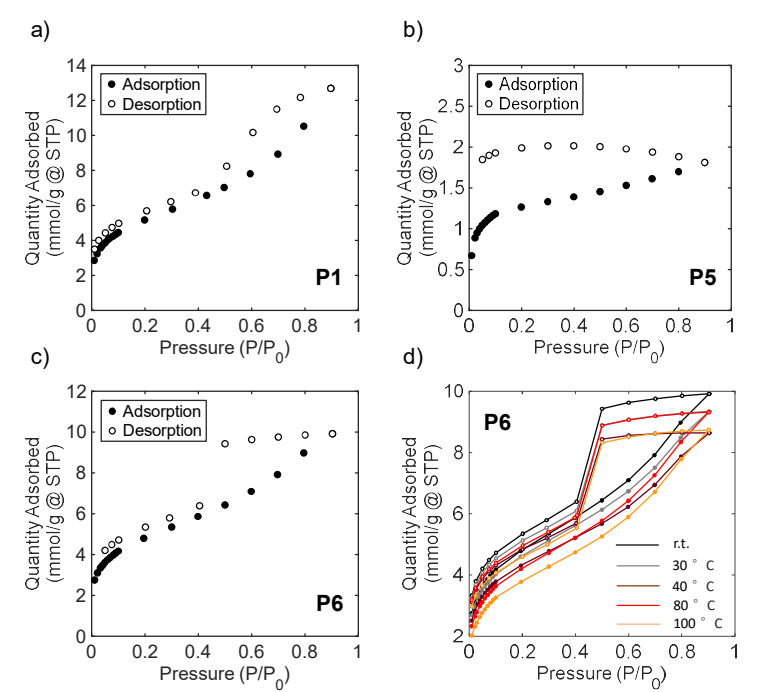

Fig. 2. (a) $\mathrm{N}_{2}$ sorption isotherm of $\mathbf{P 1}$ activated under reduced pressure ( 200 mTorr) at r.t., (b) $\mathrm{N}_{2}$ sorption isotherm of P5 activated under reduced pressure $(\sim 200$ mTorr) at r.t., (c) $\mathrm{N}_{2}$ sorption isotherm of $\mathbf{P 6}$ activated under reduced pressure ( $\sim 200$ mTorr) at r.t., and (d) $\mathrm{N}_{2}$ sorption isotherms of $\mathbf{P 6}$ activated under reduced pressure ( 200 mTorr) at r.t, $30{ }^{\circ} \mathrm{C}, 40{ }^{\circ} \mathrm{C}, 80{ }^{\circ} \mathrm{C}$ and $100^{\circ} \mathrm{C}$.

consistent with a high degree of polymerization in these polymers.

$\mathrm{N}_{2}$ gas sorption analysis was used to assess the porosity of the polymers studied herein. After activation from hexanes ${ }^{28}$ at room temperature (r.t., ca. $23^{\circ} \mathrm{C}$ ), polymer $\mathbf{P 1}$ exhibited a BET surface area of $416 \mathrm{~m}^{2} / \mathrm{g}$ (Fig. 2a), despite its being a nonnetwork polymer. The sharp rise in $\mathrm{N}_{2}$ uptake at low pressure is consistent with microporosity, and the hysteresis loop between $\mathrm{P} / \mathrm{P}_{0}=0.4$ and 0.9 is consistent with some mesoporosity as well. Pore size distribution analysis of gas sorption data by density functional theory (Figs. S49 and S50) suggest that micropores of 6-13 $\AA$ diameter contribute to ca. $70 \%$ of the polymer's surface area. These results are consistent with our contention that main-chain ferrocene can sufficiently contort the polymer backbone to support intrinsic microporosity. Activation at higher temperatures led to negligible changes in accessible surface area (Table S1, Figs. S26-S30). Given the poor solubility of P1, we next examined potential porosity in polymers $\mathbf{P 2}$ and P3. Gas sorption analysis showed that the addition of linear pendant groups led to the near-complete (for P2) and complete (for P3) elimination of measurable BET surface area $(<10$ $\mathrm{m}^{2} / \mathrm{g}$ for our analysis conditions), regardless of activation method tested (Section S2.3, ESI). Likewise, the neohexyl-containing P4 exhibited no measurable porosity. However, polymer P5, having the shortest pendant group tested (neopentyl),

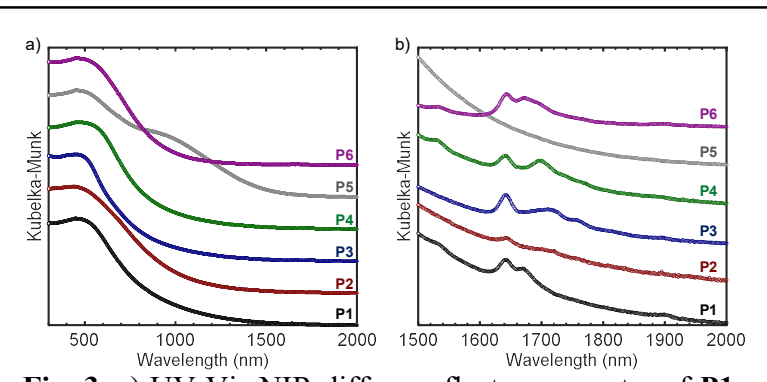

Fig. 3. a) UV-Vis-NIR diffuse reflectance spectra of P1P6 from 200-2200 nm. b) Detail of region from 1500-2000 $\mathrm{nm}$.

exhibited a BET surface area of $110 \mathrm{~m}^{2} / \mathrm{g}$ after r.t. activation. Activation of $\mathbf{P 5}$ at higher temperatures led to reductions in the BET surface area (Table S3 and Figs. S42-S43), presumably due to thermal degradation. Given the porosity of $\mathbf{P 1}$ and the combination of both solubility and porosity of P5, the copolymer P6 was synthesized from equimolar ratios of the monomers used to synthesize $\mathbf{P 1}$ and P5 (Scheme 1). P6 exhibited a BET surface area of $391 \mathrm{~m}^{2} / \mathrm{g}$ after r.t. activation and lower surface areas after higher temperature activation (Fig. 2d and Table S4). Furthermore, P6 exhibited a similar solubility profile to that of the homopolymer P5 (Table S5).

The thermal behavior of P1-P6 was assessed by thermogravimetric analysis (Figs. S51-S56). Mass loss occurred around $350{ }^{\circ} \mathrm{C}$ for P1 and P4. P2 and $\mathbf{P 3}$ began thermal decomposition around $220{ }^{\circ} \mathrm{C}$, while decomposition began at a lower temperature $\left(175^{\circ} \mathrm{C}\right)$ for P5 and P6. Mass spectrometry of the thermal decomposition products of P4 (Fig. S57) showed species of 39,41 , and 56 amu evolving from the polymer at ca. $400{ }^{\circ} \mathrm{C}$, in accordance with the mass of isobutene (Fig. S59). This fragment may be formed by proton elimination of the $t$-butyl (propyl) cation generated from the decomposition of the ethyl-t-butyl pendant groups of the polymer. Similar evolution of isobutene at ca. $400{ }^{\circ} \mathrm{C}$ was observed for P5 (Fig. S58).

Fig. 3 exhibits the solid-state UV-Vis-NIR diffuse reflectance spectra of P1-P6, and corresponding data are shown in Table 1. Absorption maxima at ca. $450 \mathrm{~nm}$ in Fig. 3 are assigned to the ferrocene $d-d$ transition. ${ }^{29-31}$ The $\pi$ $\pi^{*}$ adsorption band is present at ca. $310 \mathrm{~nm},{ }^{16}$ and the HOMO-LUMO gaps of P1-P6 range from 1.04 - 1.54 eV (Table 1). Cyclic voltammetry (CV) confirmed typical behavior expected ${ }^{16}$ for polyferrocenes (Figs. S61 and S62). UV-Vis-NIR was also used to assess evidence for mixed valency in the polymer, which can be important for intrachain charge transport. ${ }^{32}$ Absorption between 
1600-1700 nm, observed in all polymers except P5, is consistent with intervalence charge transfer (IVCT) bands seen in bridged diferrocenyl small molecules ${ }^{29,31}$ and is in accord with previous work ${ }^{16}$ showing evidence of electron exchange between ferrocene backbone units in related ferrocenyl aryleneethynylene polymers. We attribute the lack of any distinct absorption feature in this wavelength range for P5 to the poor thermal stability of this polymer. The presence of what appear to be multiple ICVT bands are tentatively attributed to the presence of distinct electronic environments within the polymer solid, although we cannot rule out the possibility of remote electron transfer ${ }^{33}$ contributing to NIR absorption as well.

In summary, we have shown that main-chain metallopolymers can possess intrinsic microporosity attributable to the organometallic constituents of the polymer backbone. Solubility and porosity, which appear to be inversely related in the ferrocene polymers studied here, can be simultaneously improved by copolymerization. These polymers can also exhibit electronic communication between ferrocene components in tandem with porosity and solubility. We term these porous, non-network metallopolymers "metallopolymers of intrinsic microporosity" (MPIMs).

\section{Conflicts of interest}

There are no conflicts to declare.

\section{Acknowledgements}

T.Z., K.G.W., and J.I.F. gratefully acknowledge generous support from the Donors of the American Chemical Society Petroleum Research Fund (\#59835-DNI10) and start-up funds from The University at Albany, State University of New York. Support for the mass spectrometer-coupled thermogravimetric analyzer was provided by the National Science Foundation Major Research Instrumentation grant \#1919810. S.R.-G. would like to thank the financial support from Natural Sciences and Engineering Research Council of Canada (NSERC) through a Discovery Grant (RGPIN2017-06611) and by the Canadian Foundation for Innovation (CFI). A.N. thanks NSERC for a doctoral scholarship.

\section{References}

(1) Xie, L. S.; Skorupskii, G.; Dincă, M. Chem. Rev. 2020 , $120,8536$.

(2) Park, H. B.; Kamcev, J.; Robeson, L. M.; Elimelech, M.; Freeman, B. D. Science 2017, 356.

(3) Koo, W.-T.; Jang, J.-S.; Kim, I.-D. Chem 2019, 5, 1938.

(4) Sun, L.; Campbell, M. G.; Dincă, M. Angew. Chem., Int.

Ed. 2016, 55, 3566.

(5) McKeown, N. B. ISRN Mater. Sci. 2012, 2012, 513986.
(6) Some porous molecular materials are soluble (M. A. Little and A. I. Cooper, Adv. Funct. Mater., 2020, 30, 1909842).

(7) Fritsch, D.; Merten, P.; Heinrich, K.; Lazar, M.; Priske, M. J. Membr. Sci. 2012, 401-402, 222.

(8) Lanč, M.; Pilnáček, K.; Mason, C. R.; Budd, P. M.; Rogan, Y.; Malpass-Evans, R.; Carta, M.; Gándara, B. C.; McKeown, N. B.; Jansen, J. C.; Vopička, O.; Friess, K. J. Membr. Sci. 2019, 570-571, 522.

(9) Budd, P. M.; Ghanem, B. S.; Makhseed, S.; McKeown, N. B.; Msayib, K. J.; Tattershall, C. E. Chem. Commun. 2004, 230.

(10) Cheng, G.; Hasell, T.; Trewin, A.; Adams, D. J.; Cooper, A. I. Angew. Chem., Int. Ed. 2012, 51, 12727.

(11) Cheng, G.; Bonillo, B.; Sprick, R. S.; Adams, D. J.; Hasell, T.; Cooper, A. I. Adv. Funct. Mater. 2014, 24, 5219.

(12) Klein, P.; Jötten, H. J.; Aitchison, C. M.; Clowes, R.; Preis, E.; Cooper, A. I.; Sprick, R. S.; Scherf, U. Polym. Chem. 2019, 10, 5200.

(13) Rodrigues, A. C. B.; Geisler, I. S.; Klein, P.; Pina, J.; Neuhaus, F. J. H.; Dreher, E.; Lehmann, C. W.; Scherf, U.; Seixas de Melo, J. S. J. Mater. Chem. C 2020, 8, 2248.

(14) Eloi, J.-C.; Chabanne, L.; Whittell, G. R.; Manners, I. Materials Today 2008, 11, 28.

(15) Sonogashira, K.; Tohda, Y.; Hagihara, N. Tetrahedron Lett. 1975, 16, 4467.

(16) Yamamoto, T.; Morikita, T.; Maruyama, T.; Kubota, K.; Katada, M. Macromolecules 1997, 30, 5390.

(17) Severin, R.; Reimer, J.; Doye, S. J. Org. Chem. 2010, 75, 3518.

(18) Novák, Z.; Szabó, A.; Répási, J.; Kotschy, A. J. Org. Chem. 2003, 68, 3327.

(19) We are actively examining this hypothesis and will report on it in due course.

(20) Odian, G. Principles of Polymerization; John Wiley \& Sons, Inc.: Hoboken, New Jersey, 2004.

(21) Sanz, B.; Ballard, N.; Marcos-Fernández, Á.; Asua, J. M.; Mijangos, C. Polymer 2018, 140, 131.

(22) Brandolini, A. J.; Hills, D. D. NMR spectra of polymers and polymer additives; CRC press, 2000.

(23) Bloembergen, N.; Purcell, E. M.; Pound, R. V. Phys. Rev. 1948, 73, 679

(24) Yamamoto, T.; Yamada, W.; Takagi, M.; Kizu, K.; Maruyama, T.; Ooba, N.; Tomaru, S.; Kurihara, T.; Kaino, T.; Kubota, K. Macromolecules 1994, 27, 6620.

(25) Cleveland, F. F.; Murray, M. J. J. Am. Chem. Soc. 1940, 62,3185 .

(26) Roy, K.; Kayal, S.; Ariese, F.; Beeby, A.; Umapathy, S. J. Chem. Phys. 2017, 146, 064303.

(27) Willis, J. N.; Ryan, M. T.; Hedberg, F. L.; Rosenberg, H. Spectrochimica Acta Part A: Molecular Spectroscopy 1968, 24,1561 .

(28) Ma, J.; Kalenak, A. P.; Wong-Foy, A. G.; Matzger, A. J. Angew. Chem., Int. Ed. 2017, 56, 14618.

(29) Levanda, C.; Bechgaard, K.; Cowan, D. O. J. Org. Chem. 1976, 41, 2700.

(30) Masahiro, K.; Izumi, M.; Motomi, K.; Yuichi, M.; Hirotoshi, S. Chem. Lett. 1988, 17, 1037.

(31) Brown, G. M.; Meyer, T. J.; Cowan, D. O.; LeVanda, C.; Kaufman, F.; Roling, P. V.; Rausch, M. D. Inorg. Chem. 1975, 14,506

(32) Holliday, B. J.; Swager, T. M. Chem. Commun. 2005, 23. 
(33) D'Alessandro, D. M.; Keene, F. R. Dalton Trans. 2006, 1060 . 